\title{
G x E Interaction Studies Using Qualitative and Quantitative Analysis Approach in Wheat (Triticum aestivum L.) in the Hot-Arid Climate of Rajasthan, India
}

\author{
Om Vir Singh, Neelam Shekhawat* and Kartar Singh
}

National Bureau of Plant Genetic Resources, Regional Station, Jodhpur, India

*Corresponding author

A B S T R A C T

\section{Keywords}

Wheat, Hot arid climate, Accession $\mathrm{x}$ environment interaction, Crossover and non-crossover interaction, Regression analysis

Article Info

Accepted: 24 September 2018 Available Online: 10 October 2018
Thirty four accessions of wheat along with checks were evaluated in four Rabi seasons of the years 2013, 2014 and 2015 and 2016 for seven quantitative traits and data were subjected to regression analysis and also the analysis to detect the presence of crossover and non-crossover interactions. Four accessions IC 535046, IC 296606, IC 78715 and IC 416388 were identified to be promising using regression analysis, whereas five accessions IC 470826, IC 535091, IC 524288, IC 78715 and IC 565529 against standard check Raj 365 were identified as potential ones by using crossover and non-crossover interactions concept. Of these accessions IC 78715 has been identified as high yielding accessions having specific adaptability and responsiveness to specific environment both by regression analysis and crossover and non-crossover interactions concept.

\section{Introduction}

Productivity of wheat in the hot- arid climate has always not been comparable to the normal climatic conditions. Wheat is cultivated during rabi season in India. To enhance productivity and production of wheat it is advocated that breeders should look for environment specific varieties which are capable of giving high yield. This becomes more important in case of wheat crop in Rajasthan to breed for their responsiveness to specific environment. Keeping in view the above, the present investigation was carried out over years during rabi seasons of the years 2013, 2014, 2015 and 2016 in the dry climate of Rajasthan to understand the GxE interaction of wheat using regression analysis (Eberhart and Russell, 1966 and Perkins and Jinks, 1968) and cross and non-crossover interactions concept (Gail and Simon, 1985). Earlier information on this aspect in wheat germplasm is not available.

\section{Materials and Methods}

Thirty four diverse accessions collected in different years from different places of India and received from abroad also along with best performing local checks i.e. Raj 365, Raj 3077 and Raj 3777 were evaluated a randomized block design with three replications over four years i.e. 2013, 2014, 2015 and 2016 during 
rabi seasons at Regional Station of National Bureau of Plant Genetic Resources, Jodhpur. Thus, evaluation was done broadly in four environments. In each environment plots consisted of four rows of $3 \mathrm{~m}$ length with row to row and plant to plant distances of $20 \mathrm{~cm}$. The thinning of experimental plots were done and efforts were made to keep plant to plant distances of $10 \mathrm{~cm}$. Recommended doses of $\mathrm{N}_{2} @ 150 \mathrm{~kg} / \mathrm{ha}, \mathrm{P}_{2} \mathrm{O}_{5} @ 60 \mathrm{~kg}$ and $\mathrm{K}_{2} \mathrm{O} / \mathrm{ha}$ @ $40 \mathrm{~kg} / \mathrm{ha}$ were also applied at different stages of growth. Recommended packages and practices were followed to raise good crop. The data were recorded on five randomly taken plants from middle rows of each plot in each environment on seed yield/plant ( $g$ ), biological yield/plant (g), harvest index (direct values were used for statistical analysis), number of seeds/spike, number of seeds per spikelet, number of fertile tillers per plant and 100-seed weight $(\mathrm{g})$ and data were analyzed separately for each environment. Adjusted progeny means were used for the combined analysis and for the traits exhibiting the presence of $\mathrm{g} x \mathrm{e}$ interaction. Regression analysis and analysis to detect the presence of crossover and non-crossover interactions were carried out as per Eberhart and Russell (1966), Perkins and Jinks (1968) and Gail and Simon (1985).

\section{Results and Discussion}

Analysis of variance revealed significant differences among accessions for the seven traits in all four seasons. The combined analysis revealed the presence of $\mathrm{g} x \mathrm{e}$ interaction for seed yield/plant (g), biological yield/plant (g), harvest index (direct values were used for statistical analysis), number of seeds/spike, number of seeds per spikelet, number of fertile tillers per plant and 100-seed weight (g). Regression analysis enables breeders to select desirable accessions with respect to the responsiveness and stability in different environments. In the studied materials the accessions IC 296606, IC 535046, IC 416388 and IC 78715 had above average performance and responsiveness with respect to seed yield/plant using regression analysis (Table 1). Among these high yielding accessions IC 296606, IC 535046 and IC 416388 can be designated as stable ones with average responsiveness.

Though the accessions IC 78715 was above average yielder and also had shown above average responsiveness coupled with instability. Accession IC 78715 was highest yielder during rabi 2014 followed by IC 416388 (2016), IC 296606 (2013) and IC 535046 (2015) were significantly superior to the best check Raj 365. The accession IC 78715 showed above average performance along with instability for seed yield per plant, biological yield/plant, 100-seed weight, number of tillers per plant and 100 seed weight being the best performance of this accession for these traits again in rabi 2014.

The regression technique describes the response pattern of individual accession without differentiating the kind of $\mathrm{g} \mathrm{x} e$ interaction involving change in magnitude of response or direction among the accessions (Baker, 1988; and Virk and Mangat 1991). Baker (1988) described a test, which was initially proposed by Gail and Simon (1985) and illustrated its application to test the kind of interaction in crop plants. The concept of crossover and non-crossover interactions is important in decision making relating to crop improvement strategies (Baker, 1988), since the presence of crossover interaction is substantial evidence in favour of breeding for specific adaptation to certain situations. Baker (1988) further suggested that in the absence of crossover interaction there is little substance for argument in the favour of breeding for adaptation to specific environment. The accessions exhibiting crossover interaction against a standard variety can be said to have 
specific adaptability and can replace that standard variety in the specific environments.

The existence of prior scientific basis to explain crossover interaction is crucial (Peto, 1982). Thus, it is advantageous to define the varietal combinations among which one has to look for qualitative interaction in advance. There will be enormous multiplicity of all possible varietal pairs for detection of crossover interaction if there is no prior basis for comparison. Such a practice will greatly increase the experiment-wise error rate. In the present case the new accessions were therefore compared with the best check Raj 365 for detection of crossover interaction since the aim was to find a suitable alternative to Raj 365.

The $\mathrm{H}$ (heterogeneity of response) and Q+ and Q- (for the presence of crossover interaction) against the standard variety Raj 365 were estimated for the 20 accessions for the traits exhibiting the presence of $\mathrm{g} x$ e interaction, i.e., seed yield/plant (g), biological yield/plant (g), harvest index (direct values were used for statistical analysis), number of seeds/spike, number of seeds per spikelet, number of fertile tillers per plant and 100-seed weight (g) and their significance was tested (Baker, 1988). The accession exhibiting either significant $\mathrm{H}$ or Q+ and Q- are given in Table 2. For seed yield/plant, $H$ was significant for the 30 accessions against Raj 365.

The presence of crossover interaction was observed for 24 accessions namely IC 279865 , IC 47336, IC 416411, IC 470826, IC 217635, IC 534283, IC 32521, IC 535091, IC 53543, IC 296440, EC 174118, EC 573571, IC 128675, IC 534957, EC 574785, IC 296485, EC 218099, IC 524288, IC 78715, EC 255113, IC 565529, IC 524302, IC 296780, EC 177796 (24 accessions) for seed yield/plant against Raj 365. The 27 accessions i.e. IC 279865, IC 47336, IC 402006, IC
535046, IC 416411, IC 470826, IC 217635, IC 532571, IC 296606, IC 32521, IC 535091, IC 531930, IC 416388, IC 53543, IC 296440, EC 217975, EC 573571, IC 534957, EC 574785, IC 296485, IC 524288, IC 78715, EC 255113, IC 565529, IC 524302, IC 296780 and EC 177796 exhibited the presence of crossover interaction for biological yield/plant. Twenty nine accessions namely, IC 279865, IC 47336, IC 402006, IC 535046, IC 416411, IC 470826,, IC 217635, IC 532571, IC 296606, IC 534283, IC 32521, IC 535091, IC 531930, IC 416388, IC 53543, IC 296440, EC 217975, EC 573571, IC 128675, IC 534957, EC 574785, IC 296485, EC 218099, IC 524288, EC 255113, IC 565529, IC 524302, IC 296780 and EC 177796 exhibited the presence of crossover $\mathrm{g} x$ e interaction for harvest index.

The 22 accessions exhibited the presence of crossover interaction for number of seeds/spike for the accessions namely, IC 47336, IC 535046, IC 416411, IC 470826, IC 217635, IC 532571, IC 534283, IC 535091, IC 416388, IC 53543, IC 296440, EC 217975, EC 573571, IC 534957, IC 296485, EC 218099, IC 524288, EC 255113, IC 565529, IC 524302, IC 296780 and EC 177796.

The presence of cross over interaction showed by the accessions IC 47336, IC 535046, IC 416411, IC 470826, IC 217635, IC 296606, IC 32521, IC 535091, IC 531930, IC 53543, IC 296440, EC 217975, EC 573571, IC 296485, EC 218099, IC 524288, IC 78715, EC 255113, IC 565529, IC 296780, EC 177796 for number of seeds per spikelet. The 25 accessions had the presence of cross over interaction for number of fertile tillers per plant were IC 279865, IC 47336, IC 416411, IC 470826, IC 217635, IC 532571, IC 534283, IC 32521, IC 535091, IC 416388, IC 53543, IC 296440, EC 217975, EC 573571, IC 128675, IC 534957, EC 574785, IC 296485, EC 218099, IC 524288, IC 78715, EC 255113, IC 565529, IC 524302, IC 296780. 
Table.1 Heterogeneity $(\mathrm{H})$ test of response for the comparison of mean seed yield/plant $(\mathrm{g})$ against the standard variety Raj 365 along with $\mathrm{Q}^{+}$and $\mathrm{Q}^{-}$values for crossover interaction and adaptability parameters for the accessions

\begin{tabular}{|c|c|c|c|c|c|c|}
\hline \multirow[t]{2}{*}{ Accession } & \multicolumn{3}{|c|}{ Adaptability Parameters } & \multicolumn{3}{|c|}{ Against Raj. 365} \\
\hline & $\mathrm{u}+\mathrm{d}_{\mathrm{i}}$ & $\mathrm{B}_{\mathrm{i}} \pm \mathrm{SE}$ & $\sigma^{2} d_{i}$ & $\mathrm{H}$ & $\mathrm{Q}^{+}$ & $\mathrm{Q}^{-}$ \\
\hline IC 111944 & 22.79 & $0.43^{*} \pm 0.21$ & $0.27^{*}$ & $33.87^{\#}$ & 101.87 & $63.88^{\$}$ \\
\hline IC 279865 & 21.84 & $0.52 * \pm 0.44$ & $0.31^{*}$ & $98.67^{\#}$ & 75.55 & $93.65^{\$}$ \\
\hline IC 296606 & 25.36 & $0.15 \pm 0.12$ & 0.05 & $44.56^{\#}$ & 45.41 & 34.42 \\
\hline \begin{tabular}{|l|} 
IC 416388 \\
\end{tabular} & 26.45 & $0.16 \pm 0.07$ & 0.09 & $83.28^{\#}$ & 64.91 & 38.11 \\
\hline IC 470826 & 21.28 & $-0.41 * \pm 0.24$ & $0.38 *$ & $93.34^{\#}$ & 106.23 & 120.84 \\
\hline \begin{tabular}{|l|} 
IC 524288 \\
\end{tabular} & 22.25 & $0.47 * \pm 0.27$ & $0.46^{*}$ & $93.64^{\#}$ & 87.48 & 109.33 \\
\hline IC 534957 & 24.80 & $0.29 * \pm 0.16$ & $0.22 *$ & $102.75^{\#}$ & $118.27^{\$}$ & 72.61 \\
\hline \begin{tabular}{|l} 
IC 535046 \\
\end{tabular} & 25.00 & $0.12 \pm 0.05$ & 0.03 & $93.98^{\#}$ & 33.24 & 119.85 \\
\hline IC 535091 & 27.66 & $0.038 * \pm 0.20$ & $0.35^{*}$ & $109.25^{\#}$ & $101.19^{\$}$ & 107.96 \\
\hline IC 565529 & 24.75 & $0.76^{*} \pm 0.38$ & $0.28 *$ & $79.16^{\#}$ & 66.37 & $93.26^{\$}$ \\
\hline IC 78715 & 26.88 & $1.34 * \pm 0.35$ & $0.25^{*}$ & $143.88^{\#}$ & 145.24 & $90.81^{\$}$ \\
\hline
\end{tabular}

- Significant at $\mathrm{P}<0.05$; \# $\mathrm{H}$ was significant against $\mathrm{x}^{2} 0.05$ at $\mathrm{s}-1 \mathrm{df}$, where $\mathrm{s}$ is the number of environments. \$ minimum of either $\mathrm{Q}^{+}$or $\mathrm{Q}^{-}$was significant against "e" value given by Gail and Simon (1985).

Table.2 Accessions exhibiting significant *, \#H (heterogeneity of response), and $\mathrm{Q}^{+}$and $\mathrm{Q}^{-}$ against standard variety Raj. 365

\begin{tabular}{|c|c|c|}
\hline Characters & $\mathbf{H}$ & $\mathbf{Q}^{+}$and $\mathbf{Q}^{-}$ \\
\hline Seed yield/plant (g) & $\begin{array}{l}\text { All accessions } \\
\text { except IC } 128675, \\
\text { IC } 325732, \text { IC } \\
524288 \text { and EC } \\
573571\end{array}$ & 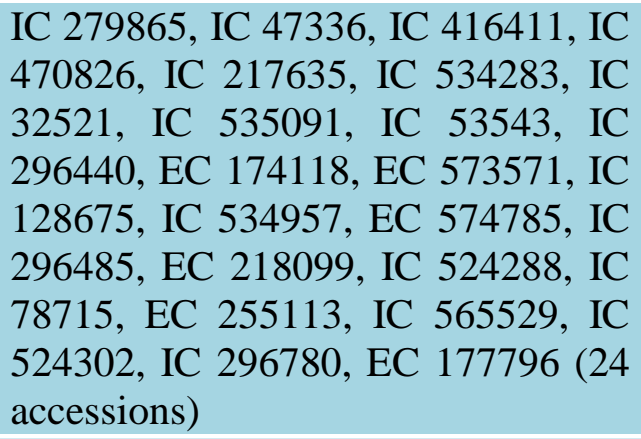 \\
\hline $\begin{array}{l}\text { Biological yield/ plant } \\
\text { (g) }\end{array}$ & $\begin{array}{l}\text { All accessions } \\
\text { except } \text { IC } 402006 \\
\text { and IC } 534283\end{array}$ & $\begin{array}{l}\text { IC } 279865 \text {, IC } 47336 \text {, IC } 402006 \text {, IC } \\
535046 \text {, IC } 416411 \text {, IC } 470826 \text {, IC } \\
217635 \text {, IC } 532571 \text {, IC } 296606 \text {, IC } \\
32521 \text {, IC } 535091 \text {, IC } 531930 \text {, IC } \\
416388 \text {, IC } 53543 \text {, IC } 296440 \text {, EC } \\
217975 \text {, EC } 573571 \text {, IC } 534957 \text {, EC } \\
574785 \text {, IC } 296485 \text {, IC } 524288 \text {, IC } \\
78715 \text {, EC } 255113 \text {, IC } 565529 \text {, IC } \\
524302 \text {, IC } 296780 \text { and EC } 177796 \text {, } \\
\text { (27 accessions) }\end{array}$ \\
\hline
\end{tabular}




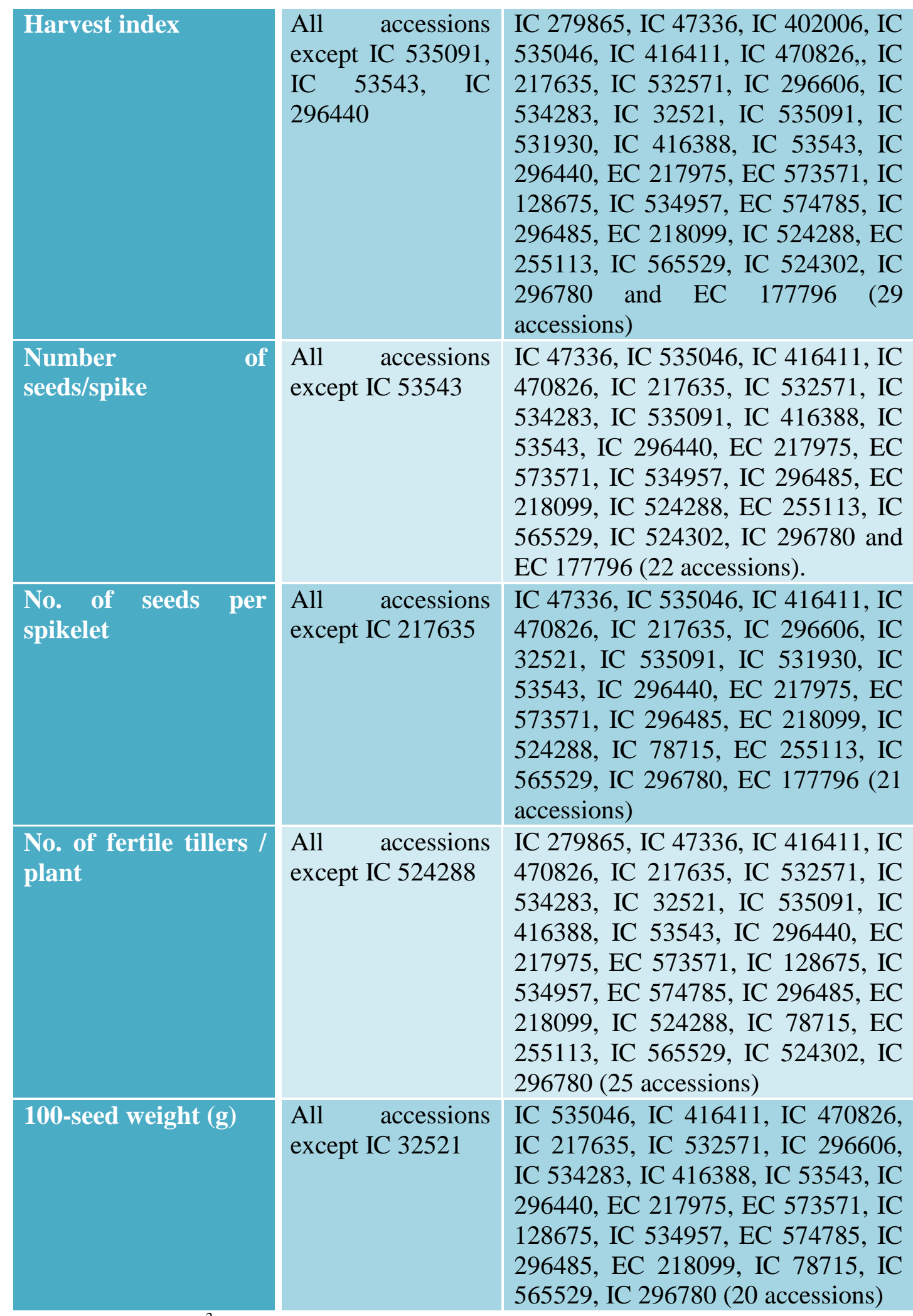

${ }^{*} \mathrm{H}$ was significant against $\mathrm{x}^{2} 0.05$ at $\mathrm{s}-1 \mathrm{df}$, where $\mathrm{s}$ is the number of environments. \# minimum of either $\mathrm{Q}^{+}$or $\mathrm{Q}$ was significant against "C" value given by Gail and Simmons (1985). 
The 20 accessions namely IC 535046, IC 416411, IC 470826, IC 217635, IC 532571, IC 296606, IC 534283, IC 416388, IC 53543, IC 296440, EC 217975, EC 573571, IC 128675, IC 534957, EC 574785, IC 296485, EC 218099, IC 78715, IC 565529, IC 296780 expressed the presence of cross over interaction for 100 seed weight. However, most of the accessions expressed the presence of crossover interaction but all accessions failed to exhibit crossover interaction for all traits against Raj 365 thus, presence or absence of crossover interaction was accession specific and trait specific (Rathore and Gupta, 1995). The accession IC 279865 and IC 78715 in rabi 2014; and IC 470826 and IC 524288 had significantly higher seed yield/plant than check Raj 365 during rabi 2015.

The conclusion drawn from regression analysis and crossover and non-crossover interactions concept about identifying accessions having specific adaptability differs considerably. The accessions IC 296606, IC 535046, IC 416388 and IC 78715 and identified as potential yielder having specific adaptability on the basis of regression analysis failed to exhibit significant min (Q+ or Q-) against standard variety Raj 365 except IC 78715 that had significant min $(\mathrm{Q}+$, Q-) against Raj 365. On the other hand the four accessions IC 470826, IC 524288, IC 565529 and IC 78715 identified as potential yielders having specific adaptability on the basis of crossover and non-crossover interaction concept, failed to exhibit stable above average performance and responsiveness for seed yield/plant except IC 78715.

A mention may be made of the accessions IC 78715 that has been identified as a high yielding one having specific adaptability both by using regression analysis and crossover and non- crossover interaction concepts. These accessions gave significantly more mean seed yield/plant than the standard variety Raj 365 . However during 2016 this had insignificant lower seed yield than Raj 365 Thus, accession IC 78715 had specific adaptation rather than possessing general adaptation (Sharma, 1995).

\section{References}

Baker, R. J. 1988. Test for crossover accessionenvironment interaction. Can. J. Plant Sel, 68: 405-410.

Eberhart S. A. and W. A. Russell. 1966. Stability parameters for comparing varieties. Crop Sci., 6: 36-40.

Gail M. and R. Simon. 1985. Testing for quantitative interaction in Schizophyllum commune. analysis and character. Heredity., 27: 361-372.

Perkins J. M. and J. L. Jinks. 1968. Environmental and accessionenvironmental components of variability IV. Non-linear interaction for multiple inbred lines. Heredity., 23: 525-535.

Peto, R. 1982. Statistical aspects of cancer trials. pp. 867-871. In: E. E. Halnan (ed.), Treatment of cancer., Chapman and Hall, London, U.K.

Rathore P. K. and V. P. Gupta. 1995. Crossover and noncrossover interactions and regression analysis for seed yield and its components in pea. Crop Improv., 21: 1418.

Sharma, R. K. 1995. Breeding lentil for response to additional nitrogen application. Crop Improv., 22: 139-141.

Virk D. S. and B. K. Mangat. 1991. Detection of crossover accession $\mathrm{x}$ environment interaction in pearlmillet. Euphytica., 52: 193-199.

\section{How to cite this article:}

Om Vir Singh, Neelam Shekhawat and Kartar Singh. 2018. G x E Interaction Studies Using Qualitative and Quantitative Analysis Approach in Wheat (Triticum aestivum L.) in the Hot-Arid Climate of Rajasthan, India. Int.J.Curr.Microbiol.App.Sci. 7(10): 3488-3493.

doi: https://doi.org/10.20546/ijcmas.2018.710.404 